\title{
SYSTEMATIC LITERATURE REVIEW: FAKTOR KEUNGGULAN KOMPETITIF HOTEL DI INDONESIA
}

\author{
Ayuk Firdawati ${ }^{1 *}$, Dwi Cahyono ${ }^{1}$, Gardina Aulin Nuha ${ }^{1}$ \\ ${ }^{1}$ Universitas Muhammadiyah Jember, Jl. Karimata No. 49 Jember, Indonesia \\ "Korespondensi: ayuk.firdawati99@gmail.com
}

\begin{abstract}
The aim of this research is to identify and evaluate the factors that give hotels in Indonesia $a$ competitive advantage. This research approach is based on a three-stage protocol, which includes an initial stage, implementation, and writing. The initial search string yielded 1,250 journal articles, of which 12 were chosen for further investigation. This study employs qualitative methods, after which the data is extracted and research questions are generated. Differentiation, environmentally friendly technology, service quality, marketing efficiency, market focus, creativity or image, leadership style, information systems, knowledge management, customer intimacy, hotel budgets, and human resources are among the factors that affect hotels' competitive advantage, according to the findings of this report. Both of these factors have a favorable or important impact on hotels' competitive advantage. Originality based on this literature can be seen as a potential research agenda and can aid the growth of the hospitality industry.
\end{abstract}

Keywords: Competitive Advantage, Hotels

\begin{abstract}
ABSTRAK
Penelitian ini bertujuan untuk mengetahui dan menganalisis faktor keunggulan kompetitif hotel di Indonesia. Metodologi penelitian ini berdasarkan adanya protokol dengan menggunakan tiga tahapan yaitu tahap awal, pelaksanaan dan penulisan. String pencarian awal ditemukan sebanyak 1.250 paper jurnal dan 12 paper jurnal dipilih untuk penelitian lebih lanjut. Penelitian ini menggunakan metode kualitatif kemudian data diekstrak dan nantinya menghasilkan pertanyaan penelitian. Temuan penelitian ini dapat menunjukkan bahwa faktor yang mempengaruhi keunggulan kompetitif hotel adalah diferensiasi, teknologi ramah lingkungan, kualitas pelayanan, kinerja pemasaran, orientasi pasar, inovasi atau citra, gaya kepemimpinan, sistem informasi, pengetahuan manajemen, keintiman pelanggan, anggaran hotel dan sumber daya manusia. Semua faktor tersebut berpengaruh secara signifikan maupun berpengaruh positif terhadap keunggulan kompetitif hotel. Orisinalitas berdasarkan adanya literatur ini tidak hanya berpedoman dari hasil penelitian, namun juga bisa dijadikan sebagai agenda riset mendatang serta dapat untuk membantu perkembangan industri perhotelan.
\end{abstract}

Kata kunci: Keunggulan Kompetitif, Hotel. 


\section{PENDAHULUAN}

Pandemi covid-19 yang ada di Indonesia mengakibatkan industri perhotelan mengalami dampak yang sangat besar. Pemberitaan adanya penutupan usaha hotel dimasa pandemi covid-19 menjadikan bencana bagi mereka. Berbagai cara dilakukan untuk mengurangi kerugian yang ditimbulkan. Selain itu, juga timbul persaingan kompetitif antar pesaing untuk mendapatkan konsumen selama pandemi covid-19 dan adanya pertumbuhan hunian hotel yang semakin meningkat pesat. Sehingga manajemen hotel perlu mempersiapkan cara agar konsumen tetap menggunakan jasa mereka (Diayudha, 2020).

Menurut Satwika \& Dewi, (2018) dalam dunia bisnis strategi perusahaan merupakan hal penting agar mampu menghadap persaingan bisnis. Meningkatkan kinerja industri perhotelan perlu menonjollkan adanya keunggulan kompetitif dari suatu produk atau jasa yang mereka miliki. Serta perlu adanya inovasi yang membuat dapat bersaing ketika persaingan semakin kompetitif. Persaingan tersebut membuat adanyanya tuntutan agar semua bisa lebih inovatif.

Keunggulan kompetitif merupakan kesatuan berdasarkan adanya ruang lingkup dari strategi yang digunakan, menggambarkan arah perusahaan secara menyeluruh dan memaksimakan sumber daya produktivitasnya. Pihak perusahaan nantinya perlu memahami keinginan konsumen (Wicaksono \& Leonandri, (2019).

Penelitian mengenai faktor keunggulan kompetitif hotel memang sudah banyak dilakukan, karena banyaknya penelitian tersebut maka banyak ditemukan ketidak konsistenan atas hasil penelitian. Selain itu, review yang membahas mengenai faktor keunggulan kompetitif hotel di Indonesia masih sangat minim, sejauh ini belum ada systematic literature review yang membahas mengenai faktor keunggulan kompetitif hotel secara luas. Hasil penelitian ini dapat bermanfaat bagi perhotelan di Indonesia untuk meningkatkan keunggulan kompetitif sehingga nantinya dapat lebih unggul atau dapat bersaing dengan industri perhotelan lainnya.

\section{METODE PENELITIAN}

\section{Desain Penelitian}

Penelitian ini dimulai dengan planning untuk tahap awal melakukan systematic literature review, selanjutnya conducting untuk tahap pelaksanaan dan terakhir reporting untuk tahapan penulisan yang nantinya menjadi sebuah laporan penelitian (Kitchenham \& Brereton, 2013)Menurut (Kitchenham \& Charters, 2007) metode yang digunakan dalam penelitian ini yaitu Systematic literature review (SLR) atau dalam bahasa indonesia disebut tinjauan pustaka sistematis adalah metode literature review yang mengidentifikasi, menilai, dan menginterpretasi seluruh temuan-temuan pada suatu topik penelitian, untuk menjawab pertanyaan penelitian (research question).

\section{Subjek dan Tempat Penelitian}

Pada penelitian ini menggunakan sebuah situs https://scholar.google.co.id/ dan http://google.com sebagai pencarian data sekunder. Subjek penelitian disini menggunakan keunggulan kompetitif hotel.

\section{Pertanyaan Penelitian (Research Question)}

Berikut ini merupakan adanya pertanyaan penelitian (research question):

RQ1 : Apa saja faktor-faktor yang dapat mempengaruhi keunggulan kompetitif hotel di Indonesia? 
RQ2 : Apa saja faktor-faktor yang secara signifikan mempengaruhi keunggulan kompetitif hotel di Indonesia?

RQ 3 : Apa metode yang digunakan untuk pengambilan data faktor keunggulan kompetitif hotel di Indonesia?

RQ4 : Apa saja permasalahan atau isu yang ditemukan dalam penelitian faktor keungguan kompetitif hotel di Indonesia?

RQ5 : Bagaimana hasil penelitian mengenai faktor keunggulan kompetitif hotel di Indonesia?

RQ6 : Penelitian mana yang mengungkapkan faktor keunggulan kompetitif hotel dibidang literatur akuntansi?

\section{Proses Pencarian (Search Process)}

Search Process diperlukan untuk mendapatkan sumber-sumber yang terkait langsung dengan persoalan yang diteliti guna menjawab research question. Proses pencarian menggunakan alamat situs https://scholar.google.co.id/ sebagai data sekunder. String pencarian berikut ini: (keunggulan kompetitif ATAU keunggulan bersaing) DAN (hotel di Indonesia * ATAU industri perhotelan).

\section{Kriteria Batasan dan Pemasukan}

Dapat dikatakan layak atau tidak jika data tersebut sudah memenuhi kriteria sebagai berikut ini:

1. Data yang digunakan menggunakan rentang waktu dari tahun 2015-2020.

2. Data yang didapatkan melalui pencarian http://scholar.google.co.id.

3. Data hanya sesuai dengan topik penelitian.

\section{Kualitas Penilaian}

Tahapan pada kualitas penilaian ditemukan akan diseleksi berdasarkan pertanyaan yang sesuai kriteria yang berkualitas sebagai berikut ini:

QA1. Apakah paper jurnal diterbitkan pada tahun 2015-2020?

QA2. Apakah paper jurnal menuliskan informasi mengenai pengembangan analisis faktor keunggulan kompetitif hotel di Indonesia?

QA3. Apakah pada paper jurnal menuliskan hasil pembahasan mengenai faktor keunggulan kompetitif hotel di Indonesia?

Pada setiap pertanyaan kriteria penilaian kualitas nantinya dapat memberikan penilaian terhadap paper jurnal yang sudah diseleksi.

1. Ya : Untuk paper jurnal yang sesuai dengan kriteria dalam penilaian kualitas.

2. Tidak : Untuk paper jurnal yang memang tidak membahas dari adnya faktor keunggulan kompetitif hotel.

\section{Pengumpulan Data (Data Collection)}

Data yang digunakan menggunakan data sekunder. Pengumpulan data penelitian ini dari beberapa tahapan yaitu observasi langsung dari sumber https://scholar.google.co.id/, studi pustaka pada data jurnal terkait yang didapatkan dari http://google.com dan dokumentasi berdasarkan data yang sudah terkumpulkan. 


\section{Peta Pemikiran}

Peta pemikiran merupakan metode untuk memaksimalkan peneliti untuk mengetahui isi pemikiran yang ada.

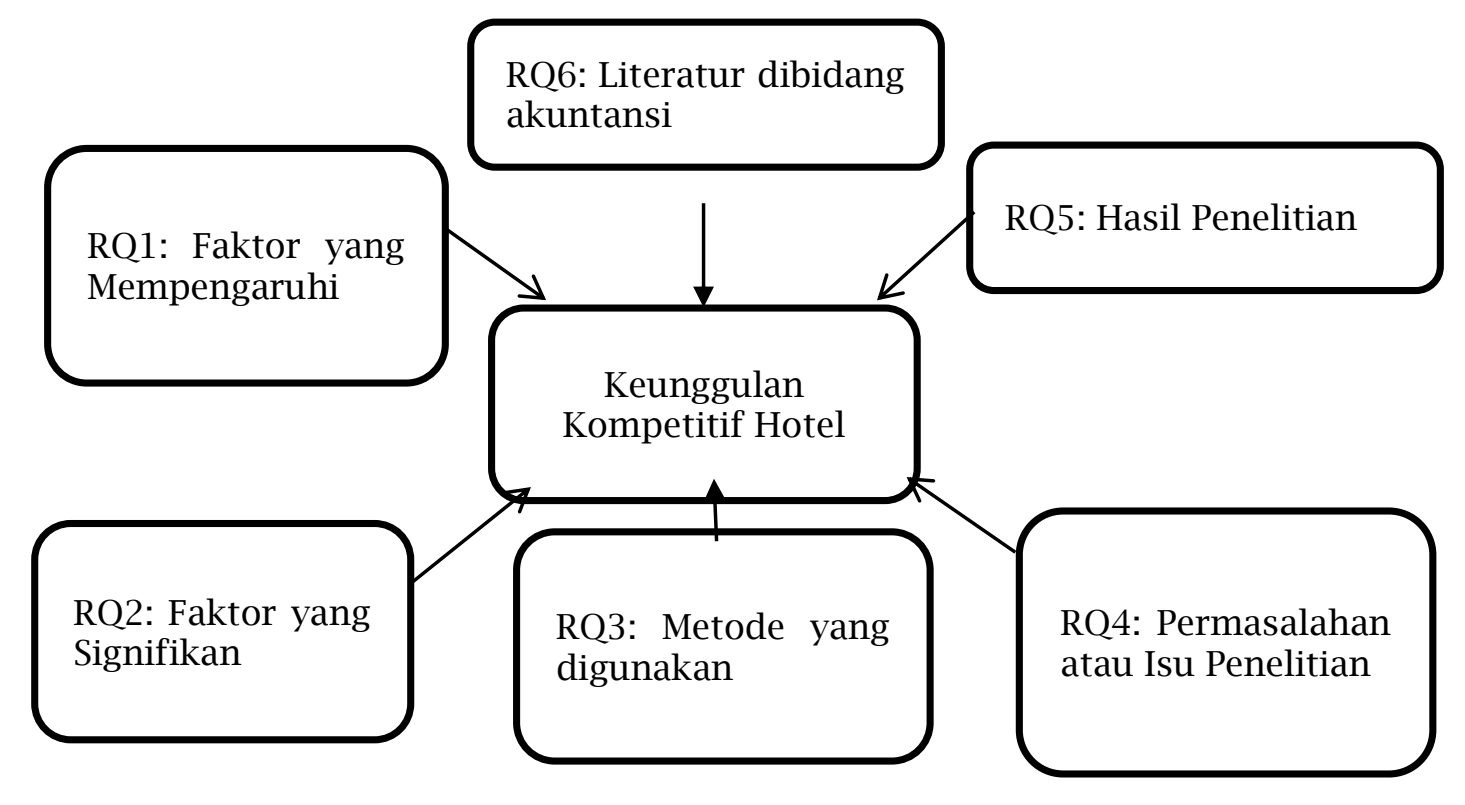

Gambar 1. Peta Pemikiran

\section{HASIL DAN PEMBAHASAN}

\section{Hasil Search Process dan Inclusion and Exclusion Criteria}

Hasil dari proses pencarian dan incusion and exclusion criteria pada penelitian ini diambil pada 12 jurnal yang diterbitkan pada rentang waktu dari tahun 2015-2020 dan hanya berkaitan dengan faktor keunggulan kompetitif hotel.

Tabel 1. Hasil Pengelompokan Berdasarkan Jenis Jurnal

\begin{tabular}{clcc}
\hline No & \multicolumn{1}{c}{ Tipe Jurnal } & Tahun & Jumlah \\
\hline 1 & Jom Fisip Volume 2 No.2 Oktober 2015 & 2015 & 1 \\
2 & E-Jurnal Manajemen Unud, Vol.6, No.7, 2017 & 2017 & 1 \\
3 & Jurnal Ilmu Administrasi Bisnis 2016 & 2017 & 1 \\
4 & Business Accounting Review, Vol. 5, No. 1, Januari & 2017 & 3 \\
& 2017 & & 1 \\
6 & Jurnal Wacana Ekonomi Fakultas Ekonomi & & 1 \\
& Universitas Garut ISSN:1412-5897 & & \\
7 & E-Jurnal Ekonomi dan Bisnis Universitas Udayana & 2017 & 1 \\
& 6.4(2017) & 2017 & 1 \\
8 & E-Jurnal Manajemen Unud, Vol.6 No 11 2017 & 1 \\
9 & Jurnal Ekobis Dewantara Vol.1 No.8 Agustus 2018 & 2018 & 1 \\
10 & Jurnal IKRA-ITH Humaniora Vol.3 No.3 November & 2019 & 1 \\
\hline & 2019 & 2016 & 1 \\
\hline
\end{tabular}




\section{Hasil dari RQ1: Faktor yang Mempengaruhi}

Tabel 2. Faktor yang Mempengaruhi

\begin{tabular}{|c|c|c|c|}
\hline No & $\begin{array}{c}\text { Faktor yang } \\
\text { mempengaruhi }\end{array}$ & Paper Penelitian & Jumlah \\
\hline 1 & Diferensiasi & $\begin{array}{l}\text { Heriyanto \& Paryanti, (2015), Nuroni, } \\
\text { (2017), dan Dewi \& Seminari, (2017) }\end{array}$ & 3 \\
\hline 2 & $\begin{array}{l}\text { Teknologi Ramah } \\
\text { Lingkungan }\end{array}$ & Sani, (2017) & 1 \\
\hline 3 & Kualitas Pelayanan & Sani, (2017) dan Dewi \& Seminari, (2017) & 2 \\
\hline 4 & Kinerja Pemasaran & $\begin{array}{l}\text { Sani, (2017), Jat \& Ngatno, (2016), dan } \\
\text { Aryana et al., (2017) }\end{array}$ & 3 \\
\hline 5 & Orientasi Pasar & Jat \& Ngatno, (2016) & 1 \\
\hline 6 & Inovasi dan Citra & $\begin{array}{l}\text { Jat \& Ngatno, (2016) dan Dewi \& Seminari, } \\
\text { (2017) }\end{array}$ & 2 \\
\hline 7 & $\begin{array}{l}\text { Gaya } \\
\text { Kepemimpinan }\end{array}$ & $\begin{array}{l}\text { Ung \& Hatane, (2017) dan Yoel \& Hatane, } \\
\text { (2016) }\end{array}$ & 2 \\
\hline 8 & Sistem Informasi & $\begin{array}{l}\text { Ung \& Hatane, (2017), Widiharta \& Hatane, } \\
\text { (2017), Aryana et al., (2017), Aji, (2018), } \\
\text { dan Setiadi \& Hatane, (2017) }\end{array}$ & 5 \\
\hline 9 & $\begin{array}{l}\text { Pengetahua } \mathrm{n} \\
\text { Manajemen }\end{array}$ & Widiharta \& Hanane, (2017) & 1 \\
\hline 10 & Customer Intimacy & Aryana et al., (2017) & 1 \\
\hline 11 & Anggaran Hotel & Wicaksono \& Leonandri, (2019) & 1 \\
\hline 12 & $\begin{array}{l}\text { Sumber Daya } \\
\text { Manusia }\end{array}$ & $\begin{array}{l}\text { Dewi \& Seminari, (2017), Yoel \& Hatane, } \\
\text { (2016), Setiadi \& Hatane, (2017), dan Aji, } \\
\text { (2018) }\end{array}$ & 4 \\
\hline
\end{tabular}

Hasil (RQ1) pada faktor yang mempengaruhi dari 12 jurnal telah ditemukan bahwa faktor yang mempengaruhi pada penelitian faktor keunggulan kompetitif hotel di Indonesia yaitu adanya diferensiasi, teknologi ramah lingkungan, kualitas pelayanan, kinerja pemasaran, orientasi pasar, inovasi atau citra, gaya kepemimpinan, sistem informasi, pengetahuan manajemen, customer intimacy, anggaran hotel dan sumber daya manusia. 12 faktor tersebut menyatakan bahwa berpengaruh secara signifikan maupun positif terhadap keunggulan kompetitif hotel di Indonesia.

\section{Hasil dari RQ2: Faktor yang Signifikan}

Diferensiasi, teknologi ramah lingkungan, kualitas pelayanan, kinerja pemasaran, orientasi pasar, inovasi atau citra, gaya kepemimpinan, sistem informasi, pengetahuan manajemen, customer intimacy, anggaran hotel dan sumber daya manusia merupakan faktor yang signifikan pada keunggulan kompetitif hotel. Namun untuk faktor yang paling signifikan menyatakan bahwa sistem informasi merupakan faktor yang dapat dikatakan berkontribusi paling baik dan dimana ditemukan dari adanya 5 jurnal pada penelitian Ung \& Hatane (2017), Widiharta \& Hatane (2017), Aryana et al., (2017), Aji (2018) dan Setiadi \& Hatane (2017) yang memang menyatakan berpengaruh signifikan maupun positif terhadap keunggulan kompetitif hotel. Seperti telihat pada gambar tabel dibawah ini. 
Tabel 3. Faktor yang Signifikan

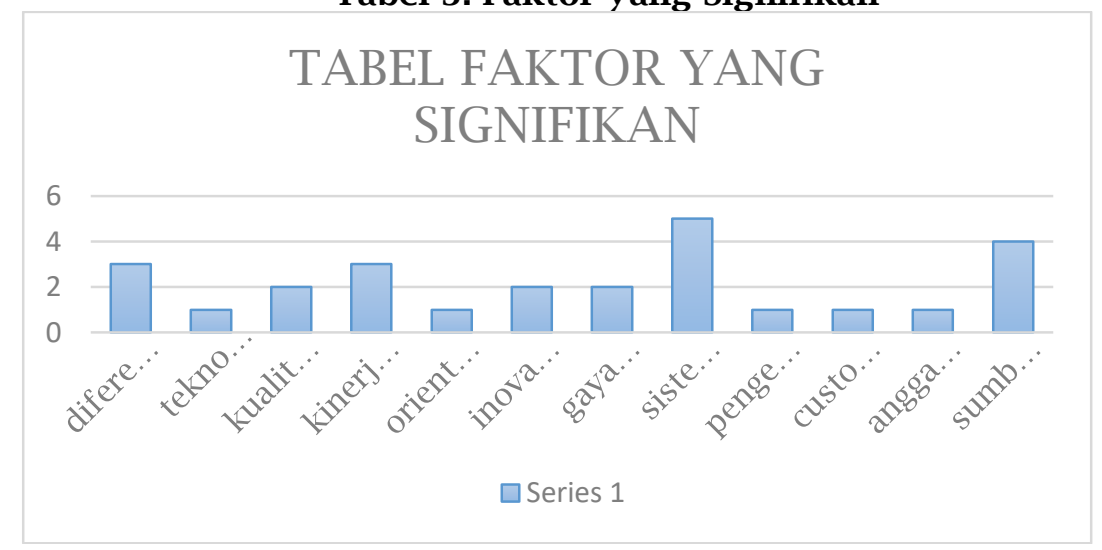

Hasil dari RQ3: Metode yang Digunakan

Tabel 4. Metode yang Digunakan

\begin{tabular}{clccc}
\hline No & \multicolumn{1}{c}{ Tipe Jurnal } & Jumlah & Metode \\
\hline 1 & Jom Fisip Volume 2 No.2 Oktober 2015 & 1 & Kuantitatif \\
2 & E-Jurnal Manajemen Unud, Vol.6, No.7, 2017 & 1 & Kuantitatif \\
3 & Jurnal Ilmu Administrasi Bisnis 2016 & 1 & Kuantitatif \\
4 & $\begin{array}{l}\text { Business Accounting Review, Vol. 5, No. 1, } \\
\text { Januari 2017 }\end{array}$ & 3 & Kuantitatif \\
6 & $\begin{array}{l}\text { Jurnal Wacana Ekonomi Fakultas Ekonomi } \\
\text { Universitas Garut ISSN:1412-5897 }\end{array}$ & 1 & Kuantitatif \\
7 & $\begin{array}{l}\text { E-Jurnal Ekonomi dan Bisnis Universitas } \\
\text { Udayana 6.4 (2017) }\end{array}$ & 1 & Kuantitatif \\
8 & $\begin{array}{l}\text { E-Jurnal Manajemen Unud, Vol. 6 No 11 2017 } \\
9\end{array}$ & 1 & Kurnal Ekobis Dewantara Vol.1 No.8 Agustus \\
10 & $\begin{array}{l}\text { 2018 } \\
\text { Jurnal IKRA-ITH Humaniora Vol.3 No.3 }\end{array}$ & 1 & Kuantitatif \\
& $\begin{array}{l}\text { November 2019 } \\
\text { Business Accounting Review 2016 }\end{array}$ & 1 & Kuantitatif \\
\hline
\end{tabular}

Hasil dari 12 jurnal yang telah ditemukan semua penelitian melakukan penelitian dengan metode kuantitatif. Pengambilan data untuk masing-masing penelitian dengan cara menggunakan kuesioner.

\section{Hasil dari RQ4: Permasalahan atau Isu Penelitian}

Hasil dari 12 jurnal mengenai permasalahan atau isu dapat diketahui bahwa penelitian dari Heriyanto \& Paryanti (2015), Jat \& Ngatno (2016), Aryana et al., (2017), Wicaksono \& Leonandri (2019), dan Setiadi \& Hatane (2017) berpendapat bahwa kebanyakan permasalahan atau isu yang terjadi pada penelitian faktor keunggulan kompetitif hotel di Indonesia kebanyakan mengenai adanya persaingan bisnis yang semakin kompetitif untuk mendapatkan konsumen yang tetap bisa menggunakan jasa atau pelayanan mereka. Selain itu, adanya upaya dari pemerintah sendiri yang lebih eksis terhadap sektor pariwisata di berbagai daerah yang di dobrak sedemikian rupa yang akhirnya menimbulkan adanya perkembangan hotel di Indonesia yang semakin meningkat pesat dari tahun ketahun. Sehingga juga menimbulkan turunnya minat konsumen jika suatu perhotelan tidak ada perkembangan atau inovasi. Industri perhotelan juga perlu mempersiapkan diri agar nantinya industri mereka tetap bertahan dan tidak terkalahkan oleh pesaing yang baru bermunculan. Perhotelan dalam menyiasati persaingan perlu untuk menciptakan hal baru. Contohnya bisa saja dari segi layanan maupun teknologi mereka. 
Sedangkan permasalahan yang timbul dari adanya penelitian pada Sani (2017), Ung \& Hatane (2017), Widiharta \& Hanane, (2017), Dewi \& Seminari (2017), dan Aji (2018) berpendapat bahwa perkembangan hotel yang semakin meningkat pesat ini juga harus diringi dengan adanya sistem informasi atau teknologi yang harus berperan dalam perkembangan perhotelan. Dimana ketika suatu perhotelan dapat menerapakan suatu sistem informasi maupun teknologi maka mereka akan bisa lebih unggul dari para pesaing yang bermunculan. Dari segi pelayanan mereka juga harus lebih inovatif dengan para pesaing sehingga para pesaing akan sulit untuk melakukan tindakan yang serupa dengan alasan ingin bersaing.

Penelitian Nuroni (2017) menyatakan bahwa pada permasalahan yang ditimbulkan atau isu yang terjadi pada keungguan kompetitif hotel yaitu karena adanya permsasalahan mengenai permintaan konsumen yang masih relatif sangat rendah. Berbeda dengan permasalahan atau isu yang terjadi pada penelitian Yoel \& Hatane (2016) mengungkapakan bahwa permasalahan yang terjadi disini karena dari segi sumber daya manusianya yang perlu dilatih sehingga nantinya akan berdampak pada kelangsungan hotel dan berpengaruh terhadap adanya keunggulan kompetitif hotel.

\section{Hasil dari RQ5: Hasil Penelitian}

Hasil dari penelitian Heriyanto \& Paryanti (2015), Nuroni (2017), Dewi \& Seminari (2017) bahwa diferensiasi berpengaruh positif maupun signifikan pada keunggulan kompetitif hotel sehingga hotel dapat bersaing dengan baik. Diferensiasi disini bisa saja dari segi adanya keunggulan pada produk atau jasa mereka, bisa juga adanya menciptakan konsumen yang loyal pada perusahaan tersebut. Berbeda dengan hasil penelitian Yoel \& Hatane (2016) dan Ung \& Hatane (2017) ditemukan bahwa gaya kepemimpinan juga ikut serta berpengaruh positif pada keunggulan kompetitif hotel.

Penelitian Setiadi \& Hatane, (2017), Aji (2018), Aryana et al., (2017), Widiharta \& Hanane (2017), Ung \& Hatane (2017) menyatakan bahwa sistem informasi menghasilkan atau berpengaruh secara signifikan dengan adanya keunggulan kompetitif yang telah ditetapkan pada industri perhotelan. Sistem informasi juga bisa dijadikan sebagai tolak ukur keberhasilan hotel agar bisa bersaing dengan para pesaingnya dengan memanfaatkan perkembangan teknologi yang ada. Selain itu juga untuk pembelajaran kepada para karyawan agar lebih mahir dalam mengoperasikan teknologi yang semakin canggih dengan sesuai pada kegunaan maupun manfaat yang telah dirasakan atau ditimbukan.

Jat \& Ngatno (2016) dan Wicaksono \& Leonandri (2019) dari hasil penelitiannya didapatkan adanya hasil orientasi pasar yang justru bisa berpengaruh terhadap adanya keunggulan kompetitif hotel. Selain hal tersebut juga perlu adanya inovasi yang harus terus berkembang sehingga pesaing tidak dapat menirukanya. Ketika suatu perusahaan dapat memiliki hal yang unik maka mereka dapat lebih unggul. Selain itu, orientasi pasar harus dapat mengikuti dengan perkembangan yang ada.

\section{Hasil dari RQ6: Literatur Dibidang Akuntansi}

Ung \& Hatane, (2017), Widiharta \& Hatane, (2017), dan Yoel \& Hatane, (2016) menyatakan bahwa penelitian dibidang akuntansi yaitu sistem informasi karena berpengaruh pada keunggulan kompetitif hotel di Indonesia dimana ketika suatu hotel dapat menerapkan atau dapat menggunakan dengan bijak nantinya dapat berpengaruh pada keunggulan kompetitif dan penelitian Setiadi \& Hatane, (2017 menyatakan bahwa gaya kepemimpinan juga terlibat pada literatur dibidang akuntansi. 
Tabel 5. Literatur Dibidang Akuntansi

\begin{tabular}{|c|c|c|c|}
\hline No & Tipe Jurnal & Penelitian & Hasil Penelitian \\
\hline 1 & $\begin{array}{l}\text { Business Accounting } \\
\text { Review, Vol. 5, No. 1, } \\
\text { Januari } 2017\end{array}$ & $\begin{array}{l}\text { Joana Edrea Ung } \\
\text { dan Saarce Elsye } \\
\text { Hatane }\end{array}$ & $\begin{array}{l}\text { Hasil dari penelitian ini adalah } \\
\text { adanya perkembangan yang pesat } \\
\text { pada industri perhotelan } \\
\text { sehingga perlu pemahaman untuk } \\
\text { terus berinovasi dan nantinya } \\
\text { tetap memberikan pelayanan } \\
\text { yang lebih baik dan unggul dalam } \\
\text { industri perhotelan yang semakin } \\
\text { kompetitif. }\end{array}$ \\
\hline 2 & Business Accounting & Arie Widiharta dan & Nantinya hasil ini dapat \\
\hline & $\begin{array}{l}\text { Review, Vol. 5, No. 1, } \\
\text { Januari } 2017\end{array}$ & $\begin{array}{ll}\text { Saarce } & \text { Elsye } \\
\text { Hanane } & \end{array}$ & $\begin{array}{l}\text { mengukur kemampuan hotel itu } \\
\text { sendiri agar bisa memiliki hal } \\
\text { yang membedakan dengan } \\
\text { pesaingnya. }\end{array}$ \\
\hline 3 & $\begin{array}{l}\text { Business Acounting } \\
\text { Review, Vol. 5, No. 1, } \\
\text { Januari 2017 (373- } \\
\text { 384) }\end{array}$ & $\begin{array}{l}\text { Kevin Setiadi dan } \\
\text { Elyse Hatane }\end{array}$ & $\begin{array}{l}\text { Hasil dari penelitian ini adalah } \\
\text { adanya persaingan yang ketat } \\
\text { antar hotel dari tahun ke tahun } \\
\text { sehingga perlu adanya } \\
\text { keunggulan bersaing agar } \\
\text { nantinya dapat bertahan. } \\
\text { Information system yang kuat } \\
\text { merupakan kunci yang sangat } \\
\text { diperlukan pada industri } \\
\text { perhotelan. }\end{array}$ \\
\hline 4 & $\begin{array}{l}\text { Business } \\
\text { Accounting } \\
\text { Review, } 2016\end{array}$ & $\begin{array}{l}\text { Fabiola Yoel dan } \\
\text { Saare Elsye Hatane }\end{array}$ & $\begin{array}{l}\text { Dimana learning organization ini } \\
\text { dapat berpengaruh untuk } \\
\text { keunggulan kompetitif pada } \\
\text { hotel. Sehingga berdampak baik } \\
\text { untuk perkembangan hotel. Gaya } \\
\text { kepemimpinan } \\
\text { berpengaruh besar terhadap } \\
\text { perkembangan hotel. }\end{array}$ \\
\hline
\end{tabular}

\section{SIMPULAN}

Berdasarkan hasil penelitian yang telah dilakukan dapat disimpulkan bahwa hasil systematic literature review dapat menganalisis sekaligus dapat memberikan informasi secara komprehensif bagi industri perhotelan. Ditemukan adanya faktor yang mempengaruhi keunggulan kompetitif hotel yaitu adanya diferensiasi, teknologi ramah lingkungan, kualitas pelayanan, kinerja pemasaran, orientasi pasar, inovasi atau citra, gaya kepemimpinan, sistem informasi, pengetahuan manajemen, customer intimacy, anggaran hotel dan sumber daya manusia.

Faktor yang mempengaruhi keunggulan kompetitif hotel semuanya memang menyatakan signifikan, namun penelitian yang paling signifikan ditemukan dari adanya sistem informasi. Metode kuantiatif merupakan metode yang difokuskan untuk meneliti pada penelitian faktor keunggulan kompetitif hotel di Indonesia. Terdapat adanya permasalahan atau isu yang terjadi yaitu karena adanya persaingan bisnis dan meningkatnya hunian hotel dari tahun ketahun. Terdapat adanya hasil penelitian yang menyatakan bahwa sistem informasi merupakan penelitian yang banyak diteliti dan masuk kedalam penelitian dibidang literatur akuntansi.

Systematic literature review ini memiliki keterbatasan karena pada umumnya penelitian ini didasarkan pada kata kunci terbatas dan juga adanya database google scholar yang digunakan untuk koleksi paper jurnal pada tahun 2015-2020. Systematic literature review untuk selanjutnya diharapkan untuk penggunaan 
sampel yang lebih banyak dengan memperluas kata kunci yang digunakan ataupun untuk menambah penggunaan rentang waktu yang digunakan untuk pencarian paper jurnal. Pada literature review dinyatakan bahwa belum adanya penelitian faktor keunggulan kompetitif hotel mengenai pandemi covid-19, maka disarankan untuk peneliti selanjutnya melakukan penelitian menenai pandemi covid-19 sehingga nantinya dapat memberikan sumber informasi yang valid untuk pengembangan penelitian mengenai faktor keunggulan kompetitif.

\section{DAFTAR RUJUKAN}

Akuntansi, P., Program, B., Akuntansi, S., Kristen, U., \& Advantage, C. (n.d.). ANALISA PENGARUH ACCOUNTING INFORMATION SYSTEM TERHADAP COMPETITIVE ADVANTAGE MELALUI KNOWLEDGE MANAGEMENT PADA INDUSTRI PERHOTELAN DI SURABAYA. 361-373.

Aryana, I N, Wardana, I. M., \& Yasa, N. N. K. (2017). Membangun Keunggulan Bersaing Melalui Kinerja Sistem Informasi Dan Customer Intimacy Dalam Meningkatkan Kinerja Pemasaran (Studi Pada Industri .... In E-Jurnal Ekonomi dan Bisnis .... ojs.unud.ac.id.

Aryana, I Nengah, Wardana, I. M., \& Ni Nyoman Kerti Yasa. (2017). Membangun Keunggulan Bersaing Melalui Kinerja Sistem Informasi Dan Customer Intimacy Dalam Meningkatkan Kinerja Pemasaran. E-Jurnal Ekonomi Dan Bisnis Universitas Udayana, 6, 1343-1364.

Dewi, B., \& Jati, K. (n.d.). PEMASARAN MELALUI KEUNGGULAN BERSAING PADA HOTEL NON Pendahuluan.

Diayudha, L. (2020). Industri Perhotelan Di Indonesia Pada Masa Pandemi Covid-19: Analisis Deskriptif. Journal FAME: Journal Food and Beverage, Product and Services, Accomodation Industry, Entertainment Services, 3(1), 41-44.

Edrea, J., \& Elsye, S. (n.d.). Pengaruh Leadership Style, Information System dan Competitive Advantage Pada Bisnis Perhotelan di Jawa Timur.

Kitchenham, B. A., \& Charters, S. (2007). Guidelines for performing systematic literature reviews in software engineering technical report. In Software Engineering Group, EBSE Technical Report ....

Nuroni, A. M., Ramdan, F. M., Ekonomi, F., Garut, U., \& Bersaing, K. (2008). KEUNGGULAN BERSAING PADA HOTEL SUMBER. 1-6.

Pembelajaran, O., Kinerja, D., Sebagai, H., \& Aji, A. B. (2018). Oleh : 1(8), 169-177.

Putu, N., \& Erna, D. (2017). MEMBANGUN KEUNGGULAN BERSAING PADA HOTEL ALILA UBUD Fakultas Ekonomi dan Bisnis Universitas Udayana , Bali, Indonesia ABSTRAK Pertumbuhan ekonomi suatu negara dapat ditopang oleh sektor pariwisata, perkebunan, pertanian, perikanan, pertambangan dan l. 6(11), 6120-6140.

Sani, A. A. (2017). Pengaruh Teknologi Ramah Lingkungan dan Kualitas Pelayanan terhadap Keunggulan Kompetitif dan Kinerja Perusahaan. In E-Jurnal Manajemen Universitas Udayana. ojs.unud.ac.id.

Setiadi, K., \& Hatane, S. E. (2017). Pengaruh Penggunaan Information System Terhadap Competitive Advantage Melalui Intellectual Capital Pada Industri Perhotelan Di Jawa Timur. Business Accounting Review.

Studi, B., Hotel, P., \& Menara, R. (2015). No Title. 2(2), 2-13. 
Wicaksono, H., \& Leonandri, D. (n.d.). STRATEGI KEUNGGULAN BERSAING HOTEL BUDGET DI AREA KEMANG - JAKARTA SELATAN Penghunian Kamar. 3(3), 4761.

Yoel, F., \& Hatane, S. E. (2016). Analisa Hubungan Leadership Style Terhadap Learning Organization Dalam Meningkatkan Competitive Advantage Pada Hotel .... Business Accounting Review. 